\title{
Chronic Pain And Health-Related Quality Of Life In Women With Autism And/Or ADHD: A Prospective Longitudinal Study
}

This article was published in the following Dove Press journal: Journal of Pain Research

\author{
Karin Asztély' \\ Svenny Kopp ${ }^{2}$ \\ Christopher Gillberg ${ }^{2}$ \\ Margda Waern (iD) ${ }^{3}$ \\ Stefan Bergman (D) ${ }^{1}$ \\ 'Department of Public Health and \\ Community Medicine, Sahlgrenska \\ Academy Institute of Medicine, \\ Göteborg, Sweden; ${ }^{2}$ Gillberg \\ Neuropsychiatric Centre, Sahlgrenska \\ Academy Institute of Neuroscience and \\ Physiology, Göteborg, Sweden; \\ ${ }^{3}$ Department of Psychiatry and \\ Neurochemistry, Sahlgrenska Academy \\ Institute of Neuroscience and Physiology, \\ Göteborg, Sweden
}

Purpose: To investigate the prevalence of chronic pain and its association with healthrelated quality of life (HRQoL) in a group of women, diagnosed with autism spectrum disorder (ASD) and/or attention deficit hyperactive disorder (ADHD) in childhood.

Patients and methods: Prospective longitudinal 16-19 years follow-up study of 100 Swedish females diagnosed with ASD and/or ADHD in childhood/adolescence. Seventyseven of the women were included in the current sub-study, using validated measures of pain perception and quality of life.

Results: A large majority of the women (76.6\%) reported chronic pain. HRQoL was low overall and lower still for those reporting chronic pain. Women with ADHD who had ongoing treatment with stimulants reported a significant lower prevalence of chronic widespread pain (CWP) than those not treated.

Conclusion: Comorbidity with chronic pain is common in women with ASD and/or ADHD and important to address in the clinic since it is associated with an already low HRQoL. Treatment for ADHD might reduce the pain in some cases.

Keywords: female, girls, attention deficit disorder, autism spectrum disorder, widespread pain, stimulants

\section{Introduction}

ADHD and ASD have been reported to be predominantly male conditions, but recent research shows that females are much more frequently affected than previously believed. ${ }^{1-3}$

ADHD is a common disorder affecting $4-7 \%$ of school-aged children, and symptoms usually persist into adulthood. ${ }^{4,5}$ The prevalence of ASD is estimated at about $1 \%{ }^{6}$ ASD is generally considered to be a lifelong disability.

The male:female ratio in ADHD is now estimated at about 1.6:1. ${ }^{1}$ The corresponding ratio in ASD is probably also less than previously assumed. ${ }^{7}$ In a recent review, it was concluded that for children meeting criteria for ASD, the ratio is close to $3: 1 .^{6}$ Recent epidemiological surveys have reported even lower male bias, 2.0-2.6:1, in the prevalence of ASD in the general population., ${ }^{2,3}$

Compared with men/boys with ADHD, women/girls with ADHD are more prone to have difficulties with inattentive symptoms than with hyperactive and impulsive symptoms, and they often receive a diagnosis of ADHD significantly later than their male counterparts. ${ }^{8}$ Girls who meet criteria for ASD are at disproportionate risk of
Correspondence: Karin Asztély Department of Public Health and Community Medicine, Sahlgrenska Academy Institute of Medicine, Box 454, Göteborg S-405 30, Sweden

Tel +46 (0)700 207580

Fax +46(0)31 7781704

Email Karin.susanna.asztely@vgregion.se 
delayed diagnosis, or remaining undiagnosed, in comparison to their male peers. Many adult women who would meet full diagnostic criteria for ASD never receive a diagnosis and the help that might come with it. ${ }^{9}$

In an Australian study examining gender differences among children meeting symptom criteria for ADHD, boys and girls did not differ on core symptoms, comorbidity, and impairment with the exception that girls rated higher on somatic complaints..$^{10}$ Daalsgard et al showed that ADHD is associated with increased mortality, which is more pronounced in women and is highest in individuals diagnosed in adulthood. ${ }^{11}$ Elevated risk for suicide attempts and self-injury has also been demonstrated compared with women in general. ${ }^{12}$

Until recently, there have only been a few published studies about adult life among individuals with ASD. The studies show a wide variability in outcomes. The role of gender remains uncertain as most studies involve few women. Moreover, there are methodological problems in conducting research of lifetime outcomes for individuals with a condition as heterogeneous as autism. ${ }^{13}$ In a register linkage study, findings indicate that nearly all major chronic medical and psychiatric conditions are significantly more common in the ASD group. Suicide attempt rates are five times higher than in patients without any autism spectrum disorder diagnoses. ${ }^{14}$ Premature mortality was markedly increased in ASD owing to a multitude of medical conditions; women had a higher relative mortality risk than men due to endocrine diseases, congenital malformations, and suicide. ${ }^{15}$

In a clinical setting, there is a common occurrence of overlapping symptoms of ADHD in ASD cases and clear traits of autism in ADHD. ${ }^{16}$ Comorbid disorders are frequent in individuals with ADHD and ASD. ${ }^{1}$ This results in a complexity when conducting surveys in these groups.

Chronic pain is a common, complex, and challenging condition. Pain is considered chronic when persistent or recurrent for more than three months. Based on the distribution of pain in the body, the condition can be defined as chronic widespread pain (CWP) or chronic regional pain (CRP). The definition of CWP according to the American College of Rheumatology (ACR) is that musculoskeletal pain should be present in both sides of the body, above and below the waist and in the axial skeleton. The more often studied condition fibromyalgia is a subgroup of CWP, characterized by CWP in combination with tenderness at 11 or more of 18 specific tender point sites, often combined with fatigue and cognitive impairment. ${ }^{17}$
Globally CWP affects one in ten individuals within the general population, with women more likely to be affected than men. ${ }^{18}$ A Swedish survey of a representative sample of the general adult population showed an age-adjusted prevalence about twice as great for women (15.3\%), as for men $(7.5 \%){ }^{19}$ There is evidence of excess mortality among persons with CWP. ${ }^{20}$

Several studies indicate that chronic pain is an issue for adolescents with emotional or behavioural problems ${ }^{21}$ and for women with ADHD symptoms. ${ }^{22,23}$ There are also some studies investigating the high frequency of ADHD found among patients with fibromyalgia. ${ }^{24-26}$ In a recent qualitative study on the perception of health professionals on frequency of painful symptoms among women with ADHD, most respondents had noted a correlation. ${ }^{27}$ Prospective clinical studies are lacking. Studies related to ASD and chronic pain appear to be scarce.

Health-related quality of life (HRQoL) is a subjective and multidimensional construct dealing with how health affects the physical, psychological, and social wellbeing of an individual. Both ASD, ADHD, and CWP are known to affect HRQoL negatively. ${ }^{28-30}$

The aim of this study was to investigate the prevalence of chronic pain in a group of women, with a childhood diagnosis of ASD and/or ADHD. A second objective was to assess HRQoL in this group of women and the possible association of chronic pain on HRQoL.

\section{Materials And Methods Study Population}

This is a part of a longitudinal 16-19 years follow-up study of a comprehensively examined cohort of females conducted in Gothenburg, Sweden. Between 1999 and 2001, 100 girls aged 3 through 18 years were examined at the Child Neuropsychiatric Clinic, Queen Silvia's Children and Youth Hospital. The girls had been referred due to social impairment, attention/academic deficits, and/ or tics. Exclusion criteria included previously diagnosed learning disabilities, severe physical disorders, and/or parents lacking adequate command of Swedish. The investigation was multi-professional, performed by very experienced clinicians, and the total number of hours spent by the girls in the assessment clinic exceeded 20 hrs in all cases. The diagnosis of ADHD and ASD, respectively, was made in accordance with the criteria of DSMIV. Of the 100 girls, 46 were diagnosed with ASD with or without co-existent ADHD and 46 had a main diagnosis of 
ADHD without ASD. Of the remaining 8, 3 had tic disorders and 5 had other psychiatric disorders. In the whole group, 12 were found to actually meet criteria for learning disabilities (after psychometric testing, in spite of having originally been "screened negative" for this disability) (see reference Kopp et $\mathrm{al}^{16}$ for more details).

During the years 2015-2018, the previously diagnosed women, now 19-37 years old, were contacted by mail, informing them about the planned study. Subsequently, they were all contacted by telephone for supplementary information before they were asked to decide on participating in the study. Four women could not be reached, and five directly declined participation. Of the 91 remaining women, 9 did not want to participate or were not able to participate on their own. However, they all gave permission for an interview with a close relative (usually the mother). Two of the women gave oral information about their present status and could be included in the study, but did not complete any questionnaires. All 91 subjects included provided informed consent.

The women were examined using 16 different instruments, some of which are semi-structured interviews. The majority of questionnaires were completed during a single interview. All three interviewers were physicians who were clinically experienced in the assessment and treatment of ASD and/or ADHD.

The present study reports on results obtained regarding self-reported estimation of pain localization and duration and self-reported HRQoL. Of the 91 women included in the main study, 80 completed questionnaires regarding pain and HRQoL; of those, 77 had a main or second diagnosis of ASD or ADHD and were included in the study. The three excluded women had diagnoses of Tourette syndrome, learning disorder, and sleep disorder.

Information regarding ongoing treatment with stimulants and possible care contacts were taken from the semistructured interview regarding the current life situation.

\section{Questionnaires}

To document experienced pain, a template with 18 predefined body regions was used. It was designed according to the ACR definition of CWP and has been used in previous studies. $^{31}$ The interviewed women were asked to tick boxes on the figure to mark all body parts where they had experienced pain for more than 3 months during the last 12 months. CWP was considered present when musculoskeletal pain for more than 3 months was described for both sides of the body, above and below the waist and in the axial skeleton. Pain lasting more than 3 months not fulfilling criteria for CWP, was considered as chronic regional pain (CRP). ${ }^{17}$ Those not fulfilling criteria for CRP or CWP were considered to have no chronic pain (NCP).

The head and the abdomen were not included in the template. Thus, the questionnaire was supplemented with the following question: "Did you have any other pain that lasted more than 3 months in the last 12 months (eg, head and abdomen)?". Free text responses were categorized as headache or abdominal pain. These results are reported separately and are not included in the category musculoskeletal chronic pain.

The Short-Form Health Survey (SF-36) was used to estimate HRQoL. SF-36 is a 36 item short form, originally constructed for the Medical Outcome study. ${ }^{32}$ The Swedish version was translated and adapted as part of the International Quality of Life Assessment (IQOLA) Project. $^{33}$ The SF-36 is a well-validated, often used health status instrument. In a follow-up study of males with ASD, SF-36 was one of the instruments used to examine subjective quality of life with satisfactory results. ${ }^{34}$ In studies assessing HRQoL in adults with ADHD, SF-36 has frequently been used and validated. ${ }^{29}$

SF-36 measures eight different health concepts: physical functioning (PF), role function-physical aspect (RP), bodily pain (BP), general health perception $(\mathrm{GH})$, vitality (VT), social functioning (SF), role function-emotional aspect (RE), and mental health (MH). SF-36 provides a score between 0 and 100 for each of the eight health concepts, where a higher score implies better health. These eight concepts measure the two major dimensions of health: physical and mental. ${ }^{35,36}$

Results in the present study group were compared to those in a population study performed in Halland, Sweden, $1995 .{ }^{19}$

\section{Ethics}

The central Ethical Review board of the University of Gothenburg has approved the study (855-14, 2015-02-17). Participation in the study was voluntary, and a written informed consent was obtained from each participant. Special arrangements were required to ensure that potential participants were fully informed. Women with ASD sometimes get stuck in formulations in the research project description and those with ADHD may experience concentration difficulties. Further, some of the women were known to have dyslexia. After feedback from the first eight participants, we realized the need for simplified study 
information. Thus, a simplified version of the letter was sent to complement the formal invitation. Oral information was provided to ensure that all participants understood what the interview/assessment would entail.

\section{Statistics}

The statistical analyses were done with IBM SPSS Statistics 23 software. T-tests were used for group comparisons of means. Chi-square tests were used for comparisons of proportions across groups. A p-value of less than 0.05 was considered statistically significant.

\section{Results}

The 77 women included in the study were born between 1981 and 1998, and they were between 19 and 37 years old at follow-up with a mean age of 27.2 (SD 4.2) years. At inclusion, in childhood, 34 (44.2\%) of the women were diagnosed with ASD as a main diagnosis. Of these, 31 had $\mathrm{ADHD}$ as a second diagnosis. Forty-one (53.2\%) had ADHD as a main diagnosis. Two women were diagnosed with Tourette syndrome or mild mental retardation as main diagnoses but fulfilled criteria for ADHD as second diagnosis. Women with $\mathrm{ADHD}$ as a main diagnosis were significantly older than those with ASD (29.1 and 25.0, respectively; $\mathrm{p}<0.001)$. Thirty-three of the women with another main diagnosis at inclusion also fulfilled criteria for ADHD as well, giving a total of 74 women $(96.1 \%)$ fulfilling the criteria in childhood.

Chronic pain was reported by $59(76.6 \%)$ of the women and the prevalence of CWP was $32.5 \%$. CWP was reported by $23.5 \%$ of those with a main diagnosis of ASD and $39.0 \%$ of those with a main diagnosis of ADHD $(p=0.313)$. The distribution of pain type by main diagnosis is visualized in Figure 1. There was no difference between women with a main diagnosis of ASD or ADHD with regard to reported number of painful regions (2.9 and 3.6 , respectively; $\mathrm{p}=0.355$ ). The most common location of pain was in the lower back, reported by $46.8 \%$, followed by the neck and shoulders (Table 1).

In the entire group of women, $20(26.0 \%)$ reported problems with recurrent headache, 23 (29.9\%) reported abdominal pain, and $11(14.3 \%)$ reported both headache and abdominal pain. There were no statistically significant differences between those with ASD and those with ADHD as main diagnosis with regard to abdominal pains (29.4\% and $31.7 \%$, respectively; $\mathrm{p}=0.830)$ or headache

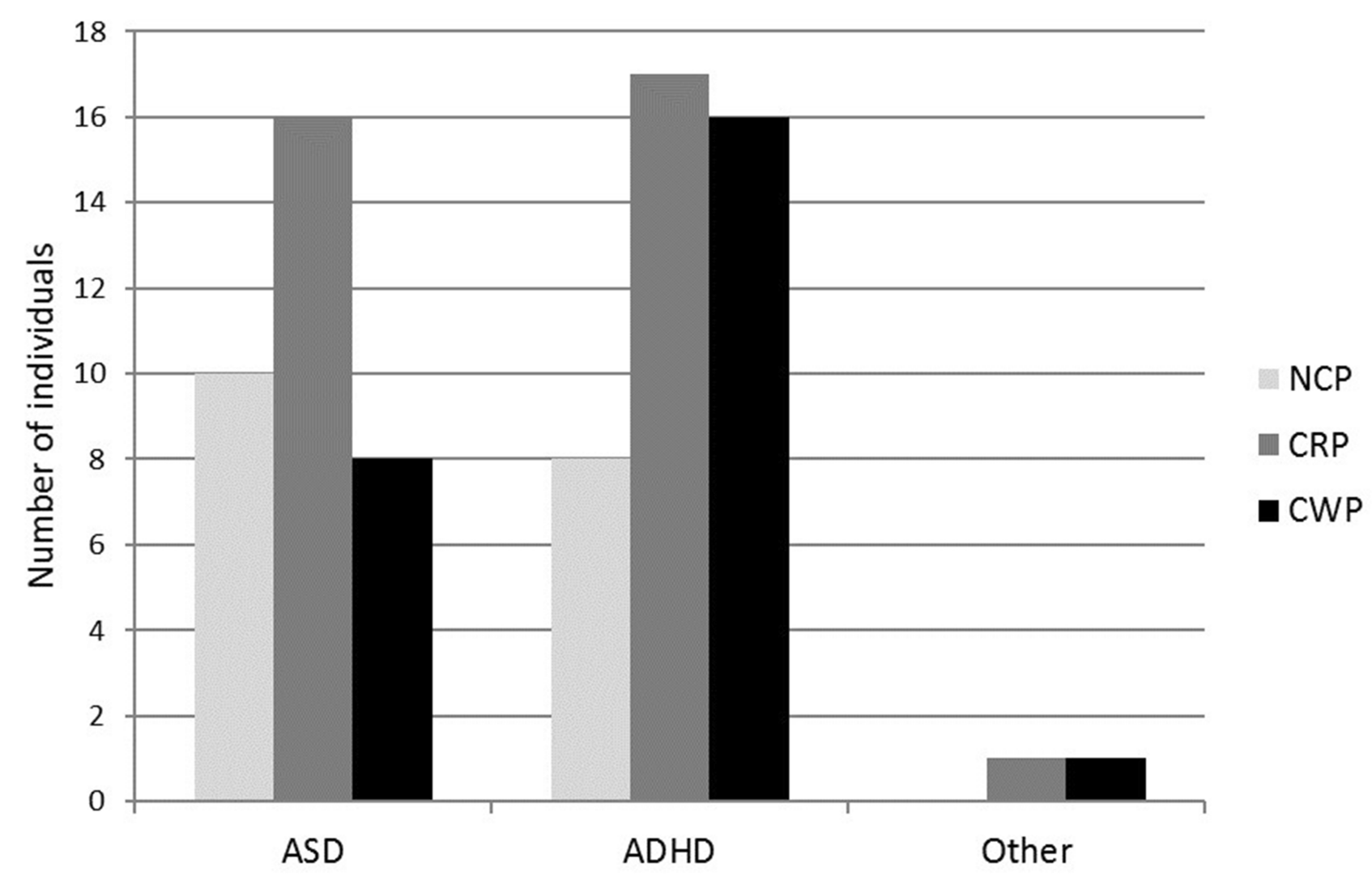

Figure I Pain type distribution (NCP, CRP, CWP) at follow-up by main diagnosis (ASD, ADHD, Other) at inclusion in childhood, presented as number of individuals. 
Table I Locations Of Chronic Pain At Follow-Up In All 77 Included Women

\begin{tabular}{|l|l|l|}
\hline & $\mathbf{n}$ & $\%$ \\
\hline Chest & 3 & 3.9 \\
Neck & 29 & 37.7 \\
Shoulder & 27 & 35.1 \\
Arm-hand & 23 & 29.9 \\
Thoracic spine & 21 & 27.3 \\
Lumbar spine & 36 & 46.8 \\
Hip-thigh & 14 & 18.2 \\
Knee & 21 & 27.3 \\
Calf-foot & 13 & 16.9 \\
Stomach & 23 & 29.9 \\
Head & 20 & 26.0 \\
\hline
\end{tabular}

(20.6\% and $31.7 \%$, respectively; $\mathrm{p}=0.278)$. Headache was present in $55.0 \%$ of those with CWP, $30.4 \%$ in CRP and $15.0 \%$ in NCP $(\mathrm{p}=0.044)$. Abdominal pain was present in $47.8 \%$ of those with CWP, $30.4 \%$ in CRP and $21.7 \%$ in NCP ( $\mathrm{p}=0.148)$. Of the women with CWP, $8(32.0 \%)$ reported both headache and stomach pain, compared to 3 (5.8\%) of the women with CRP or NCP $(\mathrm{p}=0.004)$.

HRQoL in the study population was overall significantly $(\mathrm{p}<0.001)$ lower in all eight SF-36 health concepts compared with age- and sex-specific norms. ${ }^{37}$ Those with NCP did not differ from the normal population regarding the physical dimensions of the health concepts (PF, RP, $\mathrm{GH}$, and VT) but significantly - and clinically relevant regarding the mental dimensions (SF, RE, and $\mathrm{MH}$ ). When analyzing differences between the three pain groups (NCP, CWP, and CRP), there were significant and clinically relevant differences for PF, BP, GH, and VT, but not for RP, SF, RE, or MH (Table 2) (Figure 2).

Out of those with ADHD as a main or secondary diagnosis $(n=74), 24(32.4 \%)$ had ongoing treatment with stimulants. This group reported a lower prevalence of CWP than those not treated with stimulants $(16.7 \%$ and $42.0 \%$, respectively; $\mathrm{p}=0.031$ ). There was no difference in the prevalence of CWP in those with ADHD that had a regular contact with primary or psychiatric care clinics (32.1\%) compared to those who had not $(32.1 \%$ and $38.1 \%$, respectively; $\mathrm{p}=0.622$ ).

\section{Discussion}

Chronic pain was very common in this longitudinally followed cohort of females diagnosed in childhood with ASD/ ADHD and assessed 16-18 years after initial diagnosis. HRQoL, as measured by SF-36, was lower than in the general population and even lower for those reporting CWP.

Chronic pain was reported by three-quarters of the women in the study, a proportion three times that of same-age women in the Swedish population. Widespread pain was observed in a third of the women, a figure five times that is seen in the same-age female population. ${ }^{19}$ The proportion with chronic pain was numerically greater in women with a main diagnosis of ADHD at the start of the study as compared with those with a main diagnosis of ASD, the difference, however, was not significant. This might in part be due to the relatively small sample size. Another consideration is the fact that most of the women in the ASD group also met the criteria for ADHD.

The prevalence of chronic pain in women previously diagnosed with ASD and/or ADHD in our study (76.6\%) was considerably higher than that found in the large, nationally representative 2012 Canadian Community Health Survey - Mental Health $(28.0 \%){ }^{22}$ Part of the disparity can probably be explained by methodological differences. In the Canadian study, the women were interviewed by telephone, and asked "are you usually free of pain or discomfort?". The diagnosis of ADHD was selfreported by $2.6 \%$ of the women and there are no information on data loss.

A co-variation between pain and ASD/ADHD diagnoses was also found in a Swedish study performed by Lisker et al. ${ }^{38}$ In a sample of 146 paediatric chronic pain patients (referred to a tertiary pain clinic), 38 of the

Table 2 SF-36 Scores With Regard To Pain Group (NCP, CRP, CWP) At Follow-Up For All 77 Women

\begin{tabular}{|c|c|c|c|c|c|c|c|c|c|}
\hline & \multirow[t]{2}{*}{$\mathbf{n}$} & PF & $\mathbf{R P}$ & BP & GH & VT & SF & RE & MH \\
\hline & & Mean (SD) & Mean (SD) & Mean (SD) & Mean (SD) & Mean (SD) & Mean (SD) & Mean (SD) & Mean (SD) \\
\hline $\mathrm{NCP}$ & 18 & $93.3(8.9)$ & $72.2(43.6)$ & $76.4(32.3)$ & $77.1(14.9)$ & $60.0(17.7)$ & $74.3(25.9)$ & $63.0(41.0)$ & $68.4(18.1)$ \\
\hline CRP & 34 & 87.7 (14.1) & $67.4(39.3)$ & $71.0(24.7)$ & $65.0(18.6)$ & $45.4(21.1)$ & $77.9(23.8)$ & $60.6(4 I .2)$ & $61.2(22.4)$ \\
\hline CWP & 25 & $76.4(21.7)$ & $58.3(44.0)$ & $50.0(24.9)$ & $53.3(24.1)$ & $36.5(26.6)$ & $68.8(33.0)$ & $50.0(46.1)$ & $57.0(21.0)$ \\
\hline P & & 0.003 & 0.542 & 0.003 & 0.001 & 0.005 & 0.459 & 0.551 & 0.220 \\
\hline
\end{tabular}

Note: $\mathrm{p}=$ Significance for between-group differences in ANOVA analyses. 


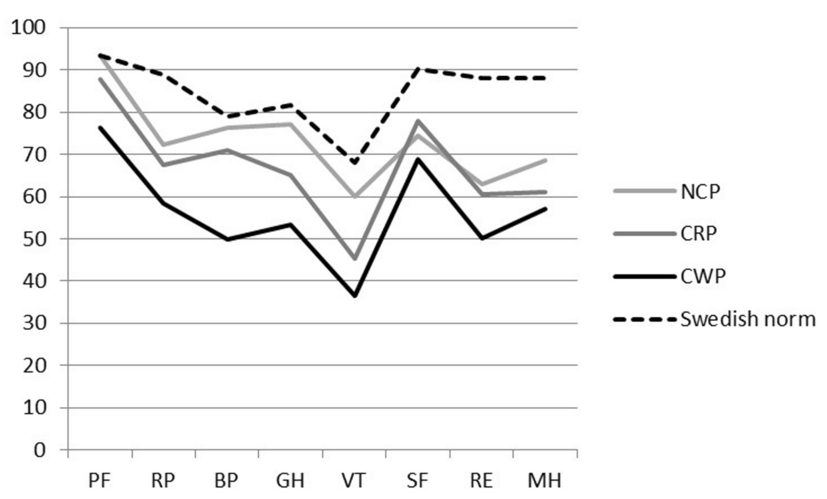

Figure 2 SF-36 scores for the different pain groups at follow up for all 77 women, with Swedish norm.

children (26\% of the total sample) had clinical features of either ASD or ADHD, or both disorders. Among children with ASD traits, girls were overrepresented, but among children with ADHD traits, there was no gender difference. These findings are in agreement with those of the Spanish study comparing women with fibromyalgia with an age-matched group of healthy women. The diagnosis in retrospect of childhood ADHD was made using a semistructured interview that contained DSM-IV criteria for ADHD. A history of childhood ADHD was found to be more common in those with fibromyalgia $(32.3 \%$ and $2.52 \%$, respectively). ${ }^{25}$

The reported pain locations in our study group are consistent with reports from women of similar age in the general population. ${ }^{19}$ This parallels findings noted in the above-mentioned study of children in a pain clinic; pain intensity, pain duration, pain frequency, pain sites, and perceived reasons for pain did not differ between children with and without clinically significant traits of ADHD or ASD. $^{38}$ From a clinical perspective, this means that women with $\mathrm{AD} / \mathrm{ADHD}$, whether diagnosed or not, could be expected to frequently seek care for the same type and location of pain as women in the rest of the population.

Headache and abdominal pain were common in this group of women. Both pain types were more frequent in women who also reported CWP or CRP, but they were frequent also in those who did not. There has been a number of studies about gastrointestinal problems and/or headache being common among children with ASD and/or ADHD, but few studies concerning adults. In the Danish Blood Donor Study with 26,456 participants (median age: 42 years, IQR $=30-52$ years), migraine was strongly associated with $\mathrm{ADHD}(\mathrm{OR}=1.8,95 \% \mathrm{CI}=1.5-2.1)$.
There was a significant interaction between age and gender, with comorbidity increasing with age and female sex. ${ }^{39}$ In a retrospective prevalence study, from three general hospital and one paediatric hospital records, including over 14,000 individuals under age 35 with ASD, $11.7 \%$ had comorbid bowel disorders (excluding those with inflammatory bowel disease). ${ }^{40}$ In our study, three-quarters of the women reporting problems with headache and abdominal pain also indicated CWP.

Reports of pain appear similar in women with or without current health care contacts, suggesting that medical services were unable to address or successfully treat pain issues. However, among women with childhood ADHD, CWP was less prevalent in those with ongoing stimulant medication compared with those without. A recent study suggested that adults with ADHD are more sensitive to pain compared with controls and that methylphenidate may affect acute pain responses in these subjects. ${ }^{41}$ In a case report by Wiwe et al, severe chronic pain in a young girl with undiagnosed comorbid ASD and ADHD, pain and function were improved, following methylphenidate medication and parental behavioural training. ${ }^{42}$ These findings are also consistent with a case report describing an adult woman treated with dexamphetamine. ${ }^{43}$

The women in our study had lower SF-36 scores than a comparable general population. The women with ASD and/or ADHD who did not report chronic pain scored about the same in SF-36 as the general population except for the mental spectrum (SF, RE, and MH). Those with chronic pain scored overall lower than the general population. This was especially prominent for those with CWP.

Although SF-36 is a generic HRQoL survey of patients perceived quality of life that frequently has been used to assess HRQoL in adults with ADHD, either solely or in combination with ADHD-specific HRQoL measures. We could identify no previous studies regarding the influence of chronic pain in adults with autism and/or ADHD on HRQoL for comparison. In several studies where HRQoL has been assessed, it has been seen that individuals with ADHD generally report lower score numbers. Using SF-36 it was found that adults with untreated ADHD had significantly lower scores than the normal population regarding the components V, SF, RE, and MH (mental components). ${ }^{44,45}$

The number of participants in our study is relatively small, and another possible limitation is that we did not include a healthy control group. Instead, we have discussed our results in relation to previous research including a group of same age women from a population study in 
a nearby part of Sweden. Nevertheless, our study has several strengths. The original clinical cohort was wellcharacterized; rigorous diagnostics criteria were applied. The drop-out rate can be considered low, especially for this type of longitudinal follow-up study. Validated instruments were used to enable comparison with population norms. Another strength is our use of a figure with predefined body regions to examine pain, as it was assumed that some of the participants might otherwise experience difficulties in reporting their pain issues. Further, individualized instruction was given by the attending examinee, facilitating adequate responses.

Girls with ASD in the original study were referred at a lower age compared to the ADHD group. This could be explained by the early occurrence of qualitative impairments in several areas of development in ASD. Girls with ADHD, the majority above 11 years when included, were assumed to be late referrals partly explained because girls do not have the same disruptive acting out problems as boys, therefore more difficult to detect. ${ }^{16}$

\section{Conclusions}

A large majority of the women with ASD and/or ADHD in our study reported chronic pain, regional or widespread, that to a great extent also impaired their HRQoL. While having chronic pain was not related to having a health care contact per se, the prevalence of chronic pain was lower in those that were prescribed stimulants. Our findings highlight the importance of the health care professionals to address pain problems in this patient group and possible unrecognized ASD and/or ADHD in women with chronic pain. Collaboration among clinicians in primary care, psychiatry, and rheumatology could facilitate treatment for women with ASD and/or ADHD and comorbid pain conditions. Randomized controlled trials regarding stimulant treatment of concomitant chronic pain in ADHD are needed.

\section{Acknowledgments}

This work was supported by the Healthcare Board, Region Västra Götaland (Hälso- och sjukvårdsstyrelsen) and by the Jane and Dan Olsson Foundation. The funding sponsors did not have a role in the design of the study, in the collection, analyses, or interpretation of data, in the writing of the manuscript, or in the decision to publish the results. The authors are grateful to Dr Agneta Kallus Rosengren for her help in performing interviews on patients included in this study.

\section{Disclosure}

The authors report no conflicts of interest in this work.

\section{References}

1. American Psychiatric Association, American Psychiatric Association DSMTF. Diagnostic and Statistical Manual of Mental Disorders: $D S M-5$. 5th ed. Arlington (VA): American Psychiatric Association; 2013.

2. Kim YS, Leventhal BL, Koh Y-J, et al. Prevalence of autism spectrum disorders in a total population sample. (Author abstract). Am J Psychiatry. 2011;168(9):904. doi:10.1176/appi.ajp.2011.11020284

3. Matilla M-L, Kielinen M, Linna S-L, et al. Autism spectrum disorders according to DSM-IV-TR and comparison with DSM-5 draft criteria: an epidemiological study. (Diagnostic and Statistical Manual for Mental Disorder)(Report). J Am Acad Child Adolesc Psychiatry. 2011;50(6):583. doi:10.1016/j.jaac.2011.04.001

4. Biederman J, Petty CR, O'Connor KB, Hyder LL, Faraone SV. Predictors of persistence in girls with attention deficit hyperactivity disorder: results from an 11-year controlled follow-up study. Acta Psychiatr Scand. 2012;125(2):147-156. doi:10.1111/j.1600-0447.2011.01797.x

5. Thapar A, Cooper M. Attention deficit hyperactivity disorder. Lancet. 2016;387(10024):1240-1250. doi:10.1016/S0140-6736(15)00238-X

6. Loomes R, Hull L, Mandy WPL. What is the male-to-female ratio in autism spectrum disorder? A systematic review and meta-analysis. $J$ Am Acad Child Adolesc Psychiatry. 2017;56(6):466-474. doi:10.1016/j. jaac.2017.03.013

7. Lai MC, Lombardo MV, Auyeung B, Chakrabarti B, Baron-Cohen S. Sex/gender differences and autism: setting the scene for future research. J Am Acad Child Adolesc Psychiatry. 2015;54(1):11-24. doi:10.1016/j.jaac.2014.10.003

8. Nussbaum NL. ADHD and female specific concerns: a review of the literature and clinical implications. J Atten Disord. 2012;16(2):87100. doi:10.1177/1087054711416909

9. Bargiela S, Steward R, Mandy W. The experiences of late-diagnosed women with autism spectrum conditions: an investigation of the female autism phenotype. J Autism Dev Disord. 2016;46(10):32813294. doi:10.1007/s10803-016-2872-8

10. Graetz BW, Sawyer MG, Baghurst P. Gender differences among children with DSM-IV ADHD in Australia. $J$ Am Acad Child Adolesc Psychiatry. 2005;44(2):159-168. doi:10.1097/00004583200502000-00008

11. Dalsgaard S, Ostergaard SD, Leckman JF, Mortensen PB, Pedersen MG. Mortality in children, adolescents, and adults with attention deficit hyperactivity disorder: a nationwide cohort study. Lancet. 2015;385(9983):2190-2196. doi:10.1016/S0140-6736(14)61684-6

12. Hinshaw SP, Owens EB, Sami N, Fargeon S. Prospective follow-up of girls with attention-deficit/hyperactivity disorder into adolescence: evidence for continuing cross-domain impairment. J Consult Clin Psychol. 2006;74(3):489-499. doi:10.1037/0022-006X.74.3.489

13. Howlin P, Magiati I. Autism spectrum disorder: outcomes in adulthood. Curr Opin Psychiatry. 2017;30(2):69-76. doi:10.1097/ YCO.0000000000000308

14. Croen LA, Zerbo O, Qian Y, et al. The health status of adults on the autism spectrum. Autism. 2015;19(7):814-823. doi:10.1177/1362361315577517

15. Hirvikoski T, Mittendorfer-Rutz E, Boman M, Larsson H, Lichtenstein P, Bolte S. Premature mortality in autism spectrum disorder. $B r J$ Psychiatry. 2016;208(3):232-238. doi:10.1192/bjp. bp.114.160192

16. Kopp S, Kelly KB, Gillberg C. Girls with social and/or attention deficits: a descriptive study of 100 clinic attenders. J Atten Disord. 2010;14(2):167-181. doi:10.1177/1087054709332458

17. Wolfe F, Smythe HA, Yunus MB, et al. The american college of rheumatology 1990 criteria for the classification of fibromyalgia. Arthritis Rheum. 1990;33(2):160-172. doi:10.1002/art.1780330203 
18. Andrews P, Steultjens M, Riskowski J. Chronic widespread pain prevalence in the general population: A systematic review. Eur $J$ Pain. 2018;22(1):5-18. doi:10.1002/ejp.1090

19. Bergman S, Herrstrom P, Hogstrom K, Petersson IF, Svensson B, Jacobsson LT. Chronic musculoskeletal pain, prevalence rates, and sociodemographic associations in a Swedish population study. $J$ Rheumatol. 2001;28(6):1369-1377.

20. Macfarlane GJ, Barnish MS, Jones GT. Persons with chronic widespread pain experience excess mortality: longitudinal results from UK Biobank and meta-analysis. Ann Rheum Dis. 2017;76(11):1815. doi:10.1136/annrheumdis-2017-211476

21. Skrove M, Romundstad P, Indredavik MS. Chronic multisite pain in adolescent girls and boys with emotional and behavioral problems: the Young-HUNT study. Eur Child Adolesc Psychiatry. 2015;24 (5):503-515. doi:10.1007/s00787-014-0601-4

22. Fuller-Thomson E, Lewis DA, Agbeyaka SK. Attention-deficit/ hyperactivity disorder casts a long shadow: findings from a population-based study of adult women with self-reported ADHD. Child Care Health Dev. 2016;42(6):918-927. doi:10.1111/cch.12380

23. Stickley A, Koyanagi A, Takahashi H, Kamio Y. ADHD symptoms and pain among adults in England. Psychiatry Res. 2016;246:326331. doi:10.1016/j.psychres.2016.10.004

24. Derksen MT, Vreeling MJ, Tchetverikov I. High frequency of adult attention deficit hyperactivity disorder among fibromyalgia patients in the Netherlands: should a systematic collaboration between rheumatologists and psychiatrists be sought? Clin Exp Rheumatol. 2015;33(1 Suppl 88):S141.

25. Reyero F, Ponce G, Rodriguez-Jimenez R, et al. High frequency of childhood ADHD history in women with fibromyalgia. Eur Psychiatry. 2011;26(8):482-483. doi:10.1016/j.eurpsy.2010.03.012

26. van Rensburg R, Meyer HP, Hitchcock SA, Schuler CE. Screening for adult ADHD in patients with fibromyalgia syndrome. Pain Med. 2017;19:1825-1831.

27. Wlad M, Nilsson B. Chronic pain and ADHD - an unexplored connection. Långvarig Smärta Och ADHD - Outforskat Samband. 2017;114:33-34.

28. Khanna R, Jariwala-Parikh K, West-Strum D, Mahabaleshwarkar R. Health-related quality of life and its determinants among adults with autism. Res Autism Spectr Disord. 2014;8(3):157-167. doi:10.1016/j. rasd.2013.11.003

29. Coghill DR, Banaschewski T, Soutullo C, Cottingham MG, Zuddas A. Systematic review of quality of life and functional outcomes in randomized placebo-controlled studies of medications for attentiondeficit/hyperactivity disorder. Eur Child Adolesc Psychiatry. 2017;26 (11):1283-1307. doi:10.1007/s00787-017-0986-y

30. Bergman S, Jacobsson LT, Herrstrom P, Petersson IF. Health status as measured by SF-36 reflects changes and predicts outcome in chronic musculoskeletal pain: a 3-year follow up study in the general population. Pain. 2004;108(1-2):115-123. doi:10.1016/j.pain.2003.12.013

31. Bergman S Chronic musculoskeletal pain: a multifactorial process. Malmö, Diss. (sammanfattning) Lund: Univeristy, 2002.
32. Tarlov AR, Ware JE Jr., Greenfield S, Nelson EC, Perrin E, Zubkoff M. The Medical Outcomes Study. An application of methods for monitoring the results of medical care. JAMA. 1989;262(7):925930. doi:10.1001/jama.262.7.925

33. Aaronson NK, Acquadro C, Alonso J, et al. International quality of life assessment (IQOLA) project. Qual Life Res. 1992;1(5):349-351.

34. Helles A, Gillberg IC, Gillberg C, Billstedt E. Asperger syndrome in males over two decades: quality of life in relation to diagnostic stability and psychiatric comorbidity. Autism. 2017;21(4):458-469. doi:10.1177/1362361316650090

35. Sullivan M, Karlsson J. The Swedish SF-36 Health Survey III. Evaluation of criterion-based validity: results from normative population. J Clin Epidemiol. 1998;51(11):1105-1113. doi:10.1016/s08954356(98)00102-4

36. Lars-Olof P, Jan K, Calle B, Bertil S, Marianne S. The Swedish SF36 Health Survey II. Evaluation of clinical validity: results from population studies of elderly and women in Gothenborg. J Clin Epidemiol. 1998;51:1095-1103. doi:10.1016/s0895-4356(98)00101-2

37. Sullivan M. SF-36 Hälsoenkät: Svensk Manual Och Tolkningsguide = (swedish Manual and Interpretation Guide). Göteborg: Sahlgrenska sjukhuset, Sektionen för vårdforskning; 1994.

38. Lipsker CW, Bolte S, Hirvikoski T, Lekander M, Holmstrom L, Wicksell RK. Prevalence of autism traits and attention-deficit hyperactivity disorder symptoms in a clinical sample of children and adolescents with chronic pain. J Pain Res. 2018;11:2827-2836. doi:10.2147/JPR.S177534

39. Hansen TF, Hoeffding LK, Kogelman L, et al. Comorbidity of migraine with ADHD in adults. BMC Neurol. 2018;18(1):147. doi:10.1186/s12883-018-1149-6

40. Kohane IS, McMurry A, Weber G, et al. The co-morbidity burden of children and young adults with autism spectrum disorders. PLoS One. 2012;7(4):e33224. doi:10.1371/journal.pone.0033224

41. Treister R, Eisenberg E, Demeter N, Pud D. Alterations in pain response are partially reversed by methylphenidate (Ritalin) in adults with attention deficit hyperactivity disorder (ADHD). Pain Pract. 2015;15(1):4-11. doi:10.1111/papr.12129

42. Wiwe Lipsker C, von Heijne M, Bolte S, Wicksell RK. A case report and literature review of autism and attention deficit hyperactivity disorder in paediatric chronic pain. Acta Paediatr. 2018;107 (5):753-758. doi:10.1111/apa.14220

43. Young JL, Redmond JC. Fibromylagia, chronic fatigue, and adult attention deficit hyperactivity disorder in the adult: a case study. Psychopharmacol Bull. 2007;40(1):118-126.

44. Adler AL, Sutton KV, Moore JR, et al. Quality of life assessment in adult patients with attention-deficit/hyperactivity disorder treated with atomoxetine. J Clin Psychopharmacol. 2006;26(6):648-652. doi:10.1097/01.jcp.0000239797.21826.70

45. Gjervan B, Torgersen T, Rasmussen K, Nordahl HM. ADHD symptoms are differentially related to specific aspects of quality of life. $J$ Atten Disord. 2014;18(7):598-606. doi:10.1177/1087054712445183
Journal of Pain Research

\section{Publish your work in this journal}

The Journal of Pain Research is an international, peer reviewed, open access, online journal that welcomes laboratory and clinical findings in the fields of pain research and the prevention and management of pain. Original research, reviews, symposium reports, hypothesis formation and commentaries are all considered for publication. The manuscript management system is completely online and includes a very quick and fair peer-review system, which is all easy to use. Visit http:// www.dovepress.com/testimonials.php to read real quotes from published authors. 